Article

\title{
Protection of Mice from Lethal Vaccinia Virus Infection by Vaccinia Virus Protein Subunits with a CpG Adjuvant
}

\author{
Sarah Reeman ${ }^{1}$, Amanda J. Gates ${ }^{1}$, David J. Pulford ${ }^{2}$ (D), Art Krieg ${ }^{3}$ and David O. Ulaeto ${ }^{1,4, *}$ \\ 1 Chemical, Biological \& Radiological Division, Dstl Porton Down, Salisbury SP4 0JQ, UK; \\ sreeman@dstl.gov.uk (S.R.); ajgates@dstl.gov.uk (A.J.G.) \\ 2 Animal Health Laboratory, Ministry for Primary Industries, Wallaceville, Upper Hutt 5140, New Zealand; \\ David.Pulford@mpi.govt.nz \\ 3 Checkmate Pharmaceuticals, One Broadway, 14th Floor, Cambridge, MA 02142, USA; \\ akrieg@checkmatepharma.com \\ 4 The Pirbright Institute, Pirbright GU24 0NF, UK \\ * Correspondence: dulaeto@dstl.gov.uk; Tel.: +44-1980-953-916
}

Received: 17 November 2017; Accepted: 4 December 2017; Published: 9 December 2017

\begin{abstract}
Smallpox vaccination carries a high risk of adverse events in recipients with a variety of contra-indications for live vaccines. Although alternative non-replicating vaccines have been described in the form of replication-deficient vaccine viruses, DNA vaccines, and subunit vaccines, these are less efficacious than replicating vaccines in animal models. DNA and subunit vaccines in particular have not been shown to give equivalent protection to the traditional replicating smallpox vaccine. We show here that combinations of the orthopoxvirus A27, A33, B5 and L1 proteins give differing levels of protection when administered in different combinations with different adjuvants. In particular, the combination of B5 and A27 proteins adjuvanted with CpG oligodeoxynucleotides $(\mathrm{ODN})$ gives a level of protection in mice that is equivalent to the Lister traditional vaccine in a lethal vaccinia virus challenge model.
\end{abstract}

Keywords: smallpox; vaccine; subunit; $\mathrm{CpG}$

\section{Introduction}

Smallpox, caused by the orthopoxvirus variola virus (VARV), was eradicated in the last century, and the virus exists now only in two World Health Organization (WHO) repositories in the USA and Russian Federation. There are continuing concerns about the possible re-emergence of smallpox through bioterrorist attacks, and the WHO and several countries have emergency preparedness plans to deal with a smallpox outbreak. Since the decline and eradication of smallpox another orthopoxvirus, monkeypox virus (MPXV) has begun to emerge as a human pathogen in Central and West Africa [1-4], and has caused a multiple foci outbreak in the USA [5]. Monkeypox appears to be controlled by smallpox vaccination, and there is likely to be an increasing need in the coming years for licensure and deployment of smallpox vaccine and/or antivirals for the control and treatment of MPXV infections.

The traditional vaccines that were successfully used to eradicate smallpox were based on a third orthopoxvirus, vaccinia virus (VACV). VACV establishes a localized infection in humans after inoculation into the skin, and the high amino acid sequence homology between old world orthopoxviruses is the basis of the success of VACV in providing immunity to smallpox. Nevertheless VACV is associated with several complications, which can be life-threatening in people who are immunocompromised [6]. Strategies to provide for contra-indicated people center on the Modified Vaccinia Ankara (MVA) strain of VACV, which does not replicate in humans because of multiple 
large-scale deletions [7-9], and the Lc16m8 strain, which is highly attenuated through deletion of the $B 5 R$ gene [10-14].

In addition there have been several studies examining DNA and protein subunit vaccines as replacement vaccines. In general, DNA vaccines have not performed as well as the traditional vaccines in mouse challenge models using virulent, non-vaccine strains of VACV [15-20]. Protein subunit vaccines have generally fared better than cognate DNA vaccine candidates, especially when used in combinations of multiple VACV proteins, and in some cases have performed as well as the Wyeth traditional vaccine $[18,21-25]$. Importantly, VACV-based DNA and subunit vaccines have been shown to protect against monkeypox in animal models, although a combination of DNA and protein subunit works better than either alone $[16,26,27]$.

Vaccination with a live virus biases towards a Th1 immune response in Balb/c mice, characterized by the induction of IgG2a antibodies, whereas immunization with protein subunits biases towards a Th2 response, characterized by the induction of IgG1 antibodies [28]. For novel vaccines against smallpox or monkeypox, the gold standard is protection equal to the traditional vaccines used in the smallpox eradication campaign. Although these could not be characterized as Th1 or Th2 inducing at the time, subsequent studies have shown that these traditional, live vaccines bias towards a Th1 response in Balb/c mice [25,29]. CpG oligodeoxynucleotides (ODN) are known to bias immune responses towards Th1 responses [30,31], and previous studies have shown that combining alum adjuvant with a CpG ODN adjuvant can alter the Th1/Th2 balance for protein subunit VACV vaccines [23]. Our study examines a panel of VACV protein subunits adjuvanted solely with CpG7909, an ODN that has been extensively researched in multiple clinical trials [32-36], as candidates for future orthopoxvirus vaccines. A combination of the B5 and A27 proteins is shown to bias strongly towards a Th1-type, IgG2a response when adjuvanted with CpG ODN, and to be most effective, comparable with the Lister traditional vaccine.

\section{Materials and Methods}

\subsection{Study Design}

6-8 week old female Balb/c mice were purchased from Charles River, UK. All mice were identified by unique microchip, and habituated for one week before sorting into random groups of 5 (Figures 1-3) or 6 (all other figures) mice per cage. Vaccinations and challenges were administered as described in the text, with variations in quantity of protein; interval between sequential vaccinations; and interval between final vaccination and challenge. For all subunit vaccinations, the appropriate protein components were combined with a fixed amount of adjuvant per dose, regardless of the amount of protein. Subunit vaccinations were given intramuscularly, and Lister vaccinations were given by scarification on a shaved flank (flanks were shaved $24 \mathrm{~h}$ prior to vaccination). After challenge, animals were monitored for 14 days, after which surviving animals were humanely culled. Mice were housed with access to food and water ad libitum, and studies were in accordance with the UK Scientific Procedures (Animals) Act 1986, and UK Codes of Practice for the Housing and Care of Animals used in Scientific Procedures 1989, under Project Licence 30/1748.

\subsection{Viruses}

VACV strains Lister, and IHD were purchased from the Swiss Serum Institute and the American Type Culture Collection (ATCC) respectively. Viruses were propagated in RK13 rabbit kidney cells in Dulbecco's modified Eagle's medium (DMEM) with 2\% fetal bovine serum (FBS), 3 mM glutamine and 100 units/mL penicillin and streptomycin (Sigma, St. Louis, MO, USA). Virus was released from infected cells by Dounce homogenization, and purified by ultra-centrifugation through a $36 \%(w / v)$ sucrose cushion. Virus was quantified by titration on monolayers of RK13 cells, and stored at $-80{ }^{\circ} \mathrm{C}$. 


\subsection{Recombinant Proteins and Adjuvants}

Constructs for expression of recombinant proteins were designed using the published sequence of the Western Reserve strain of VACV. A33 and B5 glycoproteins were produced as ectodomains in Spodoptera frugiperda Sf9 insect cells, from recombinant baculoviruses encoding the appropriate gene with an N-terminal Histidine tag (Invitrogen, Carlsbad, CA, USA). The recombinant proteins were purified on nickel agarose columns. A27 and L1 recombinant proteins were produced as glutathione-S-transferase (Gst) fusion proteins (pGEX; Pharmacia, NJ, USA) in E. coli following a $42{ }^{\circ} \mathrm{C}$ heat-shock for $1 \mathrm{~h}$ then expression at $25^{\circ} \mathrm{C}$, and purified from the soluble fraction of bacterial lysates captured on glutathione Sepharose columns before cleavage from the Gst tag with thrombin. All subunit antigens were dialyzed into phosphate buffered saline (PBS) after purification, and stored at $-20{ }^{\circ} \mathrm{C}$. For immunizations with alhydrogel, protein solutions were mixed with alhydrogel at a ratio of $1 / 5(v / v)$ and incubated at $4{ }^{\circ} \mathrm{C}$ overnight, prior to immunization. For immunizations with CpG7909, proteins were mixed with CpG7909 to give a concentration of $75 \mu \mathrm{g}$ CpG 7909 per dose, immediately prior to immunization. Alhydrogel is an aqueous colloidal suspension of $2 \%$ aluminum hydroxide (Invivogen, San Diego, CA, USA). CpG 7909 is a B-Class CpG ODN of sequence $5^{\prime}$-TCGTCGTTTTGTCGTTTTGTCGTT-3' ${ }^{\prime}$, synthesized with a phosphorothioate backbone (Coley Pharmaceutical Group, Wellesley, MA, USA).

\subsection{Mouse Challenges}

For challenge experiments VACV IHD suspended in PBS was administered in $10 \mu \mathrm{L}$ to a single nares without anesthesia. Each mouse received $5 \times 10^{6}$ pfu of virus, equivalent to $100 \times$ the median lethal dose. The weight of each mouse was recorded daily. Humane endpoints were either 30\% body weight loss or acute clinical signs. Experiments were terminated after 14 days.

\subsection{ELISA}

Enzyme linked immunosorbent assays (ELISAs) were performed by standard protocols. Up to $50 \mu \mathrm{L}$ of blood was drawn from the tail vein at appropriate intervals and centrifuged at $10,000 \times g$ for $10 \mathrm{~min}$ at room temperature, and serum collected. Recombinant proteins were adsorbed to ELISA plates in carbonate/bicarbonate ELISA coating buffer (Sigma, St. Louis, MO, USA) at $5 \mu \mathrm{g} / \mathrm{mL}$. Excess binding capacity was adsorbed with $2 \%$ milk powder, after which sera from individual mice were applied to appropriate wells at a $1 / 10$ dilution in PBS in $100 \mu \mathrm{L}$ volumes, with one well per sample. Specific binding was detected with a biotinylated goat anti-mouse IgG antibody, visualized with streptavidin-conjugated horseradish peroxidase and 2,2'-Azinobis [3-ethylbenzothiazoline-6-sulfonic acid] (ABTS, Sigma, St. Louis, MO, USA). For quantitation of IgG isotypes, isotype-specific secondary antibodies were used, and the concentrations calculated from standard curves generated with isotype standards. Optical density was measured with a $405 \mathrm{~nm}$ filter.

\subsection{Depletion of $C D 4$ and $C D 8 T$ cells}

$\mathrm{CD} 4$ and/or CD8 $\mathrm{T}$ cells were depleted in vivo by administration of three doses of rat anti-murine CD4 (clone YTS 191), and/or rat anti-murine CD8 (clone YTS 169), or rat anti-Chlamydomonas AFRC Mac5 Mabs (Chemicon, Tokyo, Japan). Animals received $500 \mu \mathrm{g}$ of each appropriate Mab on days -2 , +2 , and +6 post challenge. An additional 12 animals receiving VACV Lister were included and culled in three batches on days 0,5 and 10 post challenge to confirm depletion of spleen cells expressing the appropriate marker, by flow cytometry for CD4 (Mab clone L3T4, conjugated to PE) and CD8 (Mab clone Ly-2, conjugated to PE-Cy) (BD-Pharmingen, San Jose, CA, USA). Depletion of CD4 and CD8 cells by the appropriate treatment was confirmed, with animals given Mac5 Mab providing a negative control for depletion. The 12 animals used for confirmatory analysis were not challenged with VACV IHD. 


\subsection{Passive Transfer of Mabs}

Purified Mab to A27 or B5, or control antibody, was administered to animals in 3 doses of $50 \mu \mathrm{g}$ or $100 \mu \mathrm{g}$ per dose by intraperitoneal injection in $500 \mu \mathrm{L}$ volumes of PBS. Dosing was $2 \mathrm{~h}$ before challenge, 5 days post-challenge, and 10 days post-challenge.

\subsection{Statistical Analysis}

Analysis of variance (ANOVA) or 2-way ANOVA was performed on weight data from individual mice. Daily weight was calculated as a percentage of initial weight, and the minimum weight for each mouse post-challenge used for comparisons.

\section{Results}

We vaccinated mice with combinations of VACV proteins adjuvanted with alhydrogel or CpG7909; control VACV Lister; or PBS. Animals received 3 immunizations with proteins, at 21-day intervals. The animals were challenged with VACV strain IHD 21 days after the 3rd immunization. For the positive control, animals were scarified with VACV Lister, 28 days prior to the challenge. None of the PBS vaccinated negative control animals died. Although this was unexpected, it is not without precedent because of the wide dose range over which VACV mortality is observed in Balb/c mice, and we expect to see some survivors at the dose given [37]. Nevertheless all the PBS vaccinated negative control animals experienced heavy weight loss that approached the $30 \%$ cut-off for culling on humane grounds. The combination of A27 and A33 with either adjuvant, and all four antigens with alhydrogel, failed to provide significant protection from disease as measured by weight loss compared with PBS controls ( $p \geq 0.161$, ANOVAs). All other vaccine combinations provided a level of protection from disease ( $p$ between $0.038-0.005$ for alhydrogel, and 0.002-0.0001 for CpG, ANOVAs). However, there were marked differences between the different antigen combinations $\left(p=5.9 \times 10^{-5}\right.$, 2-way ANOVA) (Figure 1). In general, protein subunit combinations adjuvanted with $\mathrm{CpG}$ performed better than the same combination adjuvanted with alhydrogel $\left(p=6.7 \times 10^{-4}\right.$, 2-way ANOVA). The exception to this was the combination of A27 and A33 proteins, where alhydrogel marginally outperformed CpG. However this combination performed the worst of all combinations, with both adjuvants. The best performing combination was the A27 and B5 proteins with CpG adjuvant, which did not significantly differ from the positive control Lister vaccine ( $p=0.23$, ANOVA). All other combinations of antigen and adjuvant were less efficacious than the Lister vaccine ( $p \leq 0.004$, ANOVAs).

Prior to challenge, blood was drawn from vaccinated animals at 14 days after each immunization for serology, and serum stored at $-20^{\circ} \mathrm{C}$. The antibody response in vaccinated animals was assessed by ELISA against purified proteins. L1 was excluded from this analysis because it did not appear to affect the outcome of challenges, and the quantity of serum from sequential bleeds was limited. The antibody response to A27, A33 and B5 proteins was qualitatively and quantitatively different in groups that had received the relevant vaccinations. The response to A27 developed fastest, and all combinations generated a specific response; but the response to alhydrogel adjuvanted A27 developed faster than to CpG adjuvanted A27 (Figure 2A). The response to A33 was limited, with a clear positive seen in only two groups after the third bleed, with no obvious distinction between alhydrogel and CpG adjuvants (Figure 2B). A strong response to B5 was observed, and in this case, there was no apparent difference between alhydrogel and $\mathrm{CPG}$ adjuvants. Interestingly, some mice given PBS adjuvanted with CpG developed a cross-reactive response to the B5 protein while others did not (Figure 2C). 

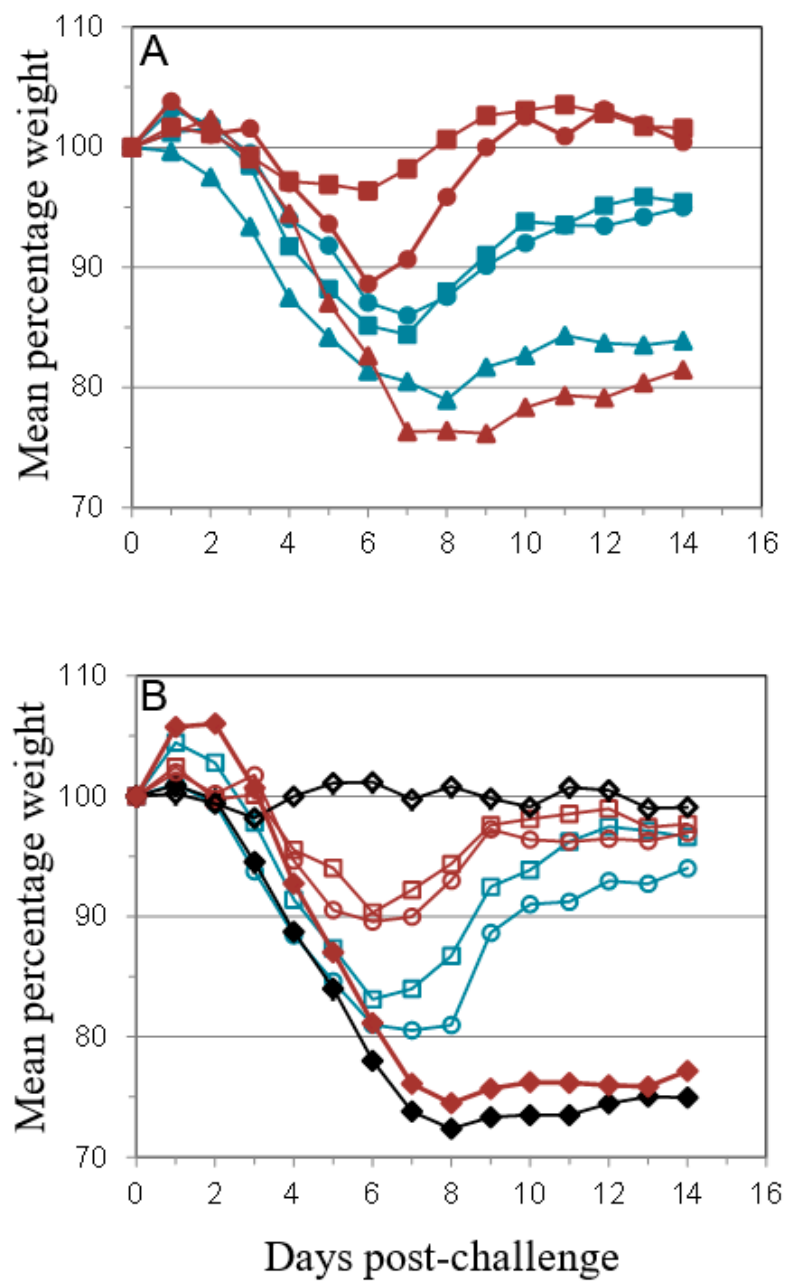

Figure 1. Vaccinia virus (VACV) Challenge of vaccinated animals. Daily post challenge weight profile for animals vaccinated with PBS $(\nabla)$; PBS/CPG $(\nabla)$; VACV Lister $(\boldsymbol{)})$; or protein subunits adjuvanted with alhydrogel or CpG; and challenged with 100 median lethal doses (MLD) of VACV IHD. Protein combinations were A27/B5/alhydrogel ( $\square$ );A27/B5/CpG ( $\square$ ); A33/B5/alhydrogel

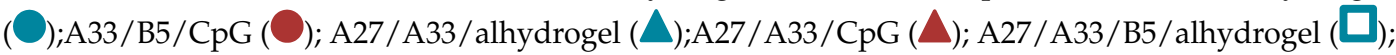
A27/A33/B5/CpG (); A27/A33/B5/L1/alhydrogel (O); or A27/A33/B5/L1/CpG (O). Each animal received $10 \mu \mathrm{g}$ (divalent, A), $6.7 \mu \mathrm{g}$ (trivalent, B) or $5 \mu \mathrm{g}$ (quadrivalent, B) of each protein for each immunization. A total of three immunizations were given at 21-day intervals, with challenge at 21 days after the 3rd immunization. PBS/CpG was administered on the same schedule as protein immunizations. Lister vaccination was given only once, with a dose of $1 \times 10^{6} \mathrm{pfu}$ on a shaved flank, as previously described [38]. Lister vaccinated animals were bled once 21 days post vaccination and challenged at 28 days post vaccination, with the other groups. PBS controls were on the same schedule as Lister vaccination. Data is presented as daily means of the weight of each surviving animal as a percentage of its initial weight. Statistical analysis was by Analysis of Variance (ANOVA) and 2-way ANOVA. 

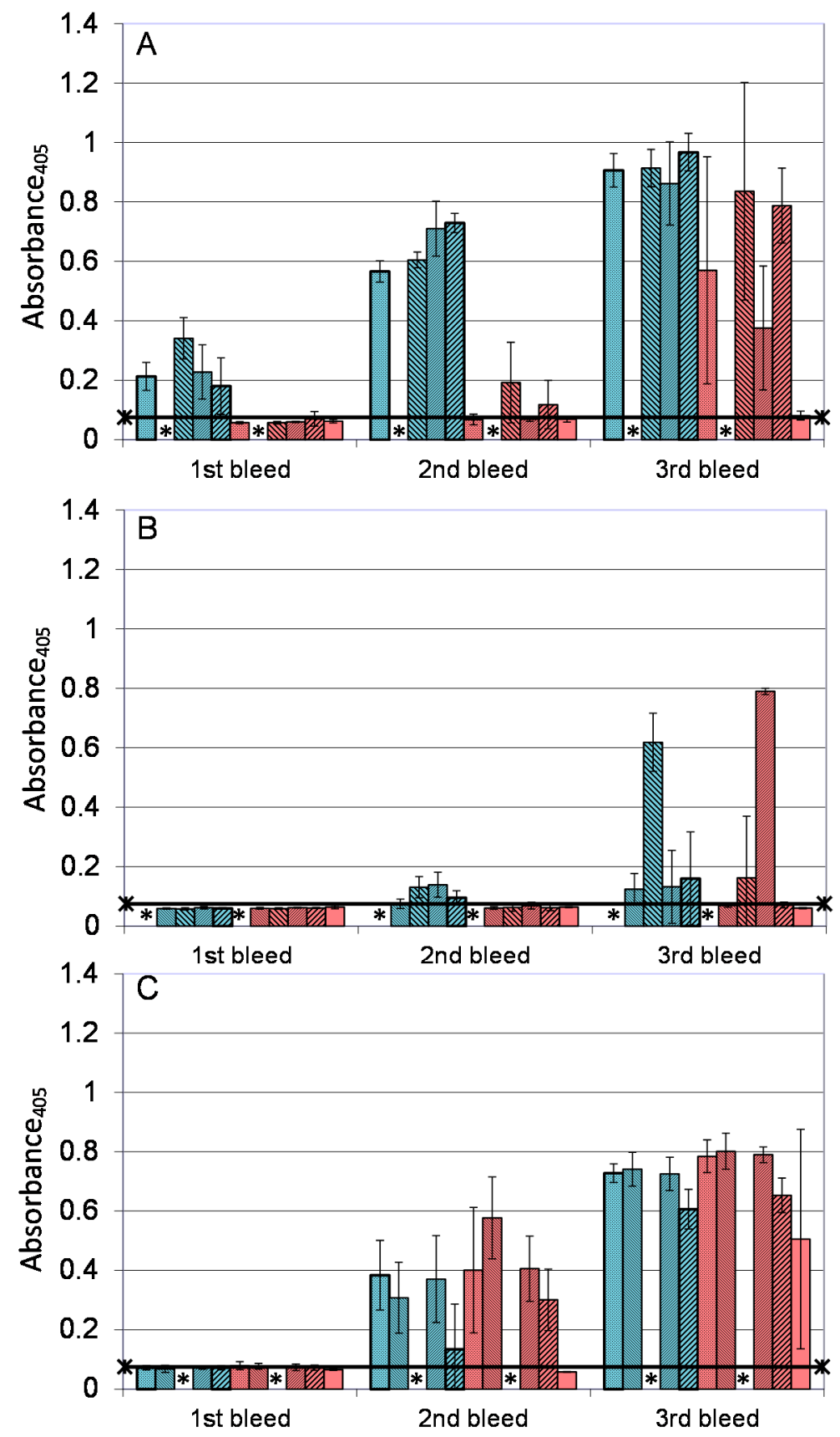

Figure 2. Antibody responses after vaccination. Antibody responses in animals from Figure 1 were assessed by Enzyme linked immunosorbent assay (ELISA) against purified A27 (A), A33 (B) or B5 (C) proteins. Primary antibodies were sera from animals immunized with A27/B5/alhydrogel (

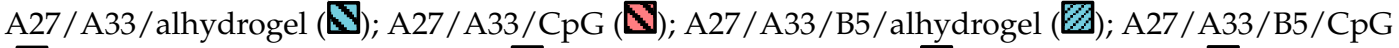
$(\mathbb{Z}) ;$ A27/A33/B5/L1/alhydrogel $(\boldsymbol{Q}) ; \mathrm{A} 27 / \mathrm{A} 33 / \mathrm{B} 5 / \mathrm{L} 1 / \mathrm{CpG}(\boldsymbol{\square})$; and PBS/CpG $(\square)$, and bled 14 days after each immunization. * Not done. ELISA data is presented as means and standard deviations of samples from five animals ( 1 well/animal). $n=$ five animals/group. Horizontal bar represents the mean of the negative control, plus $2 \times$ standard deviations.

The response to A27 and B5 proteins was further assessed for IgG isotypes in sera from the third bleed. For A27, IgG1 predominated over IgG2 in recipients of alhydrogel adjuvanted material. This was reversed when CpG was used as an adjuvant, with the IgG1 component reduced relative to 
alhydrogel, and the IgG2a component increased relative to alhydrogel ( $p=0.003$, ANOVA) (Figure 3A). A similar picture was found with responses to B5 protein ( $p=0.006$, ANOVA) (Figure 3B).
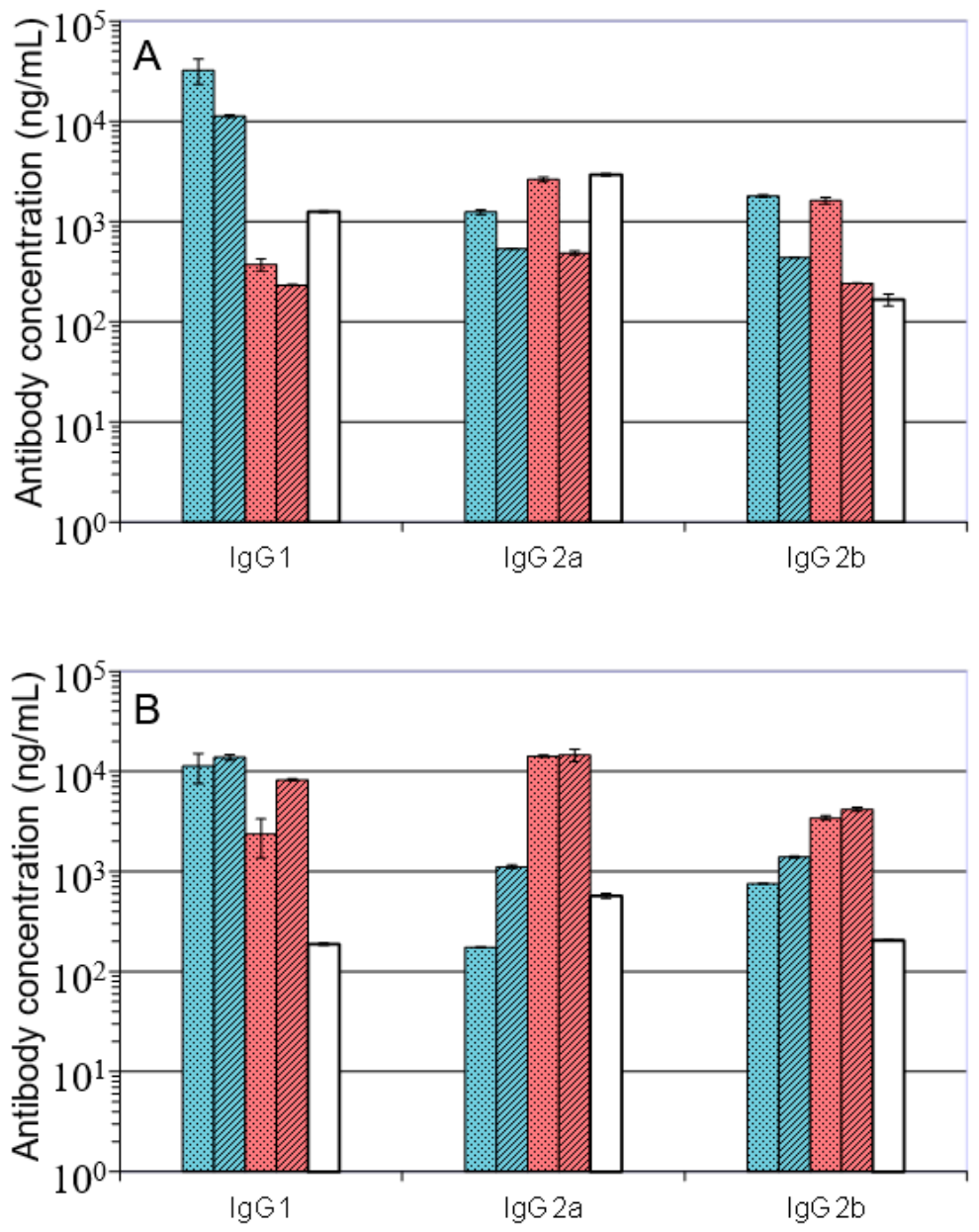

Figure 3. IgG isotype of antibody responses to subunit proteins. Pooled sera from the 3rd bleed of selected groups described in Figure 1 ( 5 animals per pool) were applied to ELISA plates coated with A27 (A) or B5 (B) proteins in triplicate wells. IgG isotypes were quantitated with isotype specific secondary antibodies, and data fitting to standard curves for each isotype. A27/B5/alhydrogel (B);

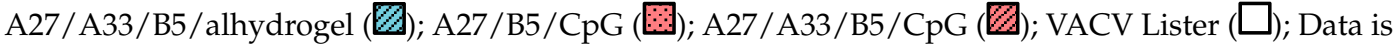
presented as means and standard deviations of triplicate wells.

In the previous experiment, the total quantity of protein immunogen in each regimen was constant, and the quantity of each component thus varied with the number of components in the mix. To examine whether the negative effect of including A33 and/or L1 with A27 and B5 was due to the reduction in quantity of A27 and/or B5R in the tri- and quadrivalent mixes, a further experiment was undertaken to assess the influence of antigen concentration on the efficacy of B5R and A27 combinations. This experiment also examined the effect of dosing interval.

Reducing the amount of A27 and B5 proteins in divalent mixes had little or no effect on the level of protection from subsequent challenge, using both the high and low concentrations from Figure 1 (10 $\mu \mathrm{g}$ and $5 \mu \mathrm{g} /$ animal respectively of each protein) (Figure 4A). Cutting the interval between 1st and 2nd immunizations from 21 to 14 days gave the appearance of a significant improvement in efficacy as measured by minimum weight in the post-challenge period (Figure 4B). However this was not statistically significant ( $p=0.22$, ANOVA). To confirm this, an alternative analysis was performed using the cumulated daily weights post-challenge for each animal instead of the minimum weight, 
and again, no significant difference was observed ( $p=0.24$, ANOVA). Similarly, extending the interval between the 3rd immunization and the challenge from 21 days to 56 days resulted in the appearance of an increase in morbidity measured by weight loss (Figure 4C), but this was not significant for comparisons of minimum or cumulated weight ( $p=0.3$ and 0.18 respectively, ANOVAs).

To further examine the effect of compressing the immunization schedule an additional experiment was performed in which all the immunization intervals, and the interval between 3rd immunization and challenge, were reduced to 14 days, for both CpG7909 and alhydrogel adjuvanted A27 and B5 proteins. This further compression reduced the efficacy of the vaccination relative to the Lister vaccine, and the level of protection was the same as that achieved with alhydrogel as an adjuvant $(p=0.2$, ANOVA) (Figure 4D).

To examine the role played by cell mediated immunity in protecting from disease in this model, we took mice immunized with A27 and B5 proteins in CpG 7909 adjuvant, and depleted CD4+, CD8+, or CD4+ and CD8+ T cells prior to challenge with VACV IHD. T cell depletions were performed by administration of depleting monoclonal antibodies (Mabs) to the appropriate $\mathrm{T}$ cell marker, or a control antibody to a non-relevant antigen. In all situations, vaccinated animals were protected relative to unvaccinated controls ( $p \leq 0.002$, ANOVAs). For CpG 7909 adjuvanted A27 and B5 proteins, depletion of CD4+ cells, singly or in combination with depletion of CD8+ cells, did not alter efficacy relative to animals receiving the non-relevant antibody ( $p=0.48$ and 0.49 respectively, ANOVAs). However, depletion of CD8+ cells alone appeared to increase the efficacy of the vaccine with respect to weight loss, with a $P$ value between the confidence limits $(p=0.016$, ANOVA; average percentage difference 6.4\%) (Figure 5A). Conversely, where Lister vaccinated animals were depleted of CD8+ cells, singly or in combination with depletion of $\mathrm{CD} 4+$ cells, there was no difference in efficacy relative to animals receiving the non-relevant antibody ( $p=0.05$ and 0.09 respectively, ANOVAs). However, animals depleted of CD4+ cells alone appeared to show increased efficacy relative to those receiving non-relevant antibody ( $p=0.006$, ANOVA; average percentage difference 5.3\%) (Figure 5B). There was no statistical difference between subunit/CpG7909 and Lister vaccinated animals, receiving the non-relevant antibody ( $p=0.65$, ANOVA).

In a final experiment we assessed the ability of two Mabs, to A27 and B5, to protect mice from VACV challenge. Mabs were administered to animals by intraperitoneal injection at doses of $50 \mu \mathrm{g}$ and $100 \mu \mathrm{g}$ per animal, singly or in combination. Control animals received an equal quantity of non-relevant rat IgG, or mouse IgG from animals previously vaccinated with VACV Lister. $24 \mathrm{~h}$ after administration, animals were challenged with VACV as for previous experiments. 4/6 animals receiving $50 \mu \mathrm{g}$, and 5/6 receiving $100 \mu \mathrm{g}$ of anti-A27 died after VACV challenge, similar to the animals receiving non-relevant rat IgG. However, all animals receiving anti-B5 Mab, singly or in combination, survived. All animals receiving anti-Lister $100 \mu \mathrm{g}$ Lister IgG survived, but only $50 \%$ of those receiving the $50 \mu \mathrm{g}$ dose survived (Figure 6A,B). When weight profiles were examined, with the exception of treatment with anti-B5, no treatment was equivalent to vaccination with the Lister vaccine ( $p \leq 1.4 \times 10^{-7}$, ANOVAs). For treatment with anti-B5 Mab, singly or in combination with anti-A27, $50 \mu \mathrm{g}$ doses of Mab were less efficacious than Lister vaccine ( $p \leq 0.002$, ANOVAs), while treatment with $100 \mu \mathrm{g}$ Mab was equivalent to Lister vaccination $(p \geq 0.06)$, with respect to minimum weight post-challenge. There was no difference between minimum weight of animals treated with anti-B5 or anti-B5 with anti-A27 ( $p=0.32$, 2-way ANOVA), but anti-B5 alone or in combination was more efficacious than any other antibody treatment $(p \leq 0.0002,2$-way ANOVAs). Nevertheless, treatment with anti-Lister IgG was more efficacious than treatment with anti-A27 Mab or non-relevant $\operatorname{IgG}\left(p=4.3 \times 10^{-5}\right.$ and 0.004 respectively, 2-way ANOVAs). However, treatment with anti-A27 Mab offered no benefit over the non-relevant IgG control ( $p=0.12$, 2-way ANOVA). 

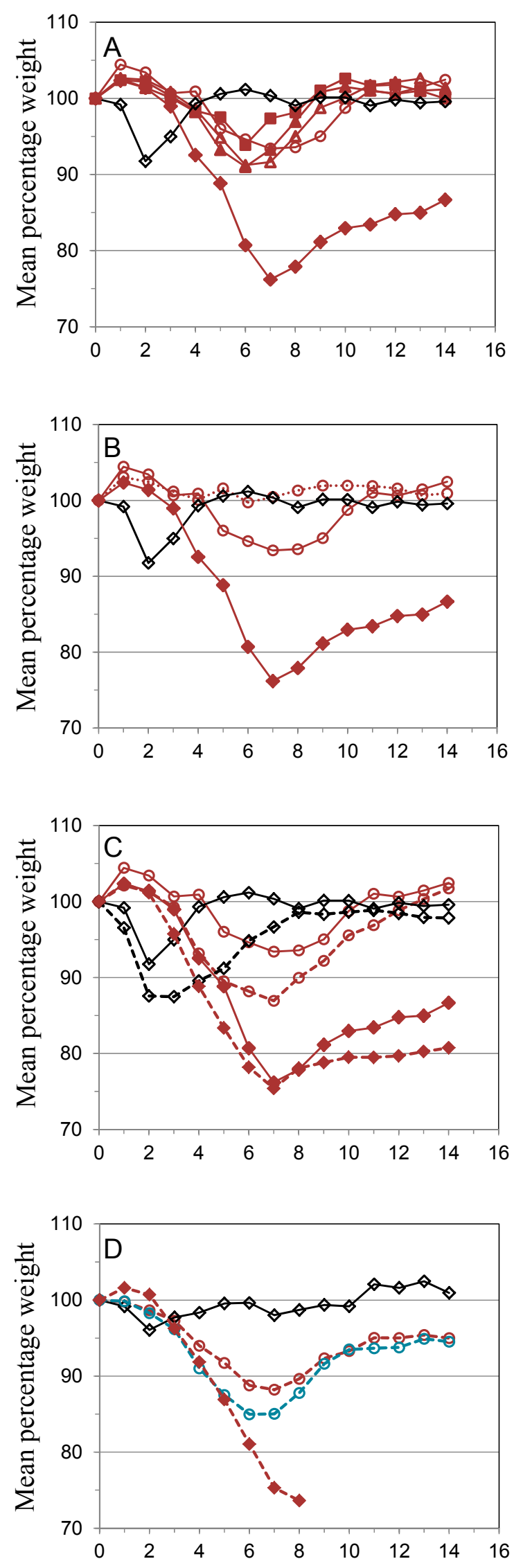

Days post-challenge 
Figure 4. Effects of protein concentration and altered dosing interval. Animals were vaccinated with divalent A27/B5/CpG vaccines under the same dosing/challenge schedule as for Figure 1, with protein concentrations (per dose) of $5 \mu \mathrm{g}$ A27 and $5 \mu \mathrm{g}$ B5 (- - $) ; 10 \mu \mathrm{g}$ A27 and $10 \mu \mathrm{g}$ B5 ( $\square$ ); $5 \mu \mathrm{g} \mathrm{A27}$ and $10 \mu \mathrm{g}$ B5 $(\mathbf{\Delta}) ; 10 \mu \mathrm{g}$ A27 and $5 \mu \mathrm{g}$ B5 $(\mathbf{\Delta}) ;(\mathbf{A})$. In the same experiment the dosing schedule for animals receiving $5 \mu \mathrm{g} /$ dose of each protein was varied to reduce the interval between 1 st and 2 nd immunizations to 14 days (" - - " " "), with all other aspects unchanged (B). Also in the same experiment the interval between the $3^{\text {rd }}$ immunization and challenge was extended to 56 days for animals receiving

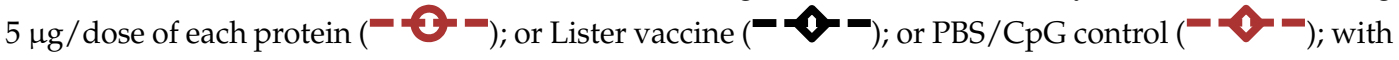
all other aspects unchanged (C). In a separate experiment the dosing schedule for animals receiving $5 \mu \mathrm{g} /$ dose of each protein $(\boldsymbol{-}-\boldsymbol{T}-$ ) was varied to reduce all immunization intervals and the 3rd immunization/challenge interval to 14 days for material adjuvanted with CpG7909 (- $-\mathbf{-}$ ); or alhydrogel (- $-\mathbf{-}$ ); or PBS/CpG control (- - - $)$; with all other aspects unchanged (D). Controls in all panels are Lister vaccine ( schedule as for Figure 1. Weight data is presented as daily means of the weight of each surviving animal as a percentage of its initial weight. Statistical analysis was by ANOVA and 2-way ANOVA. $n=6$ animals per group.
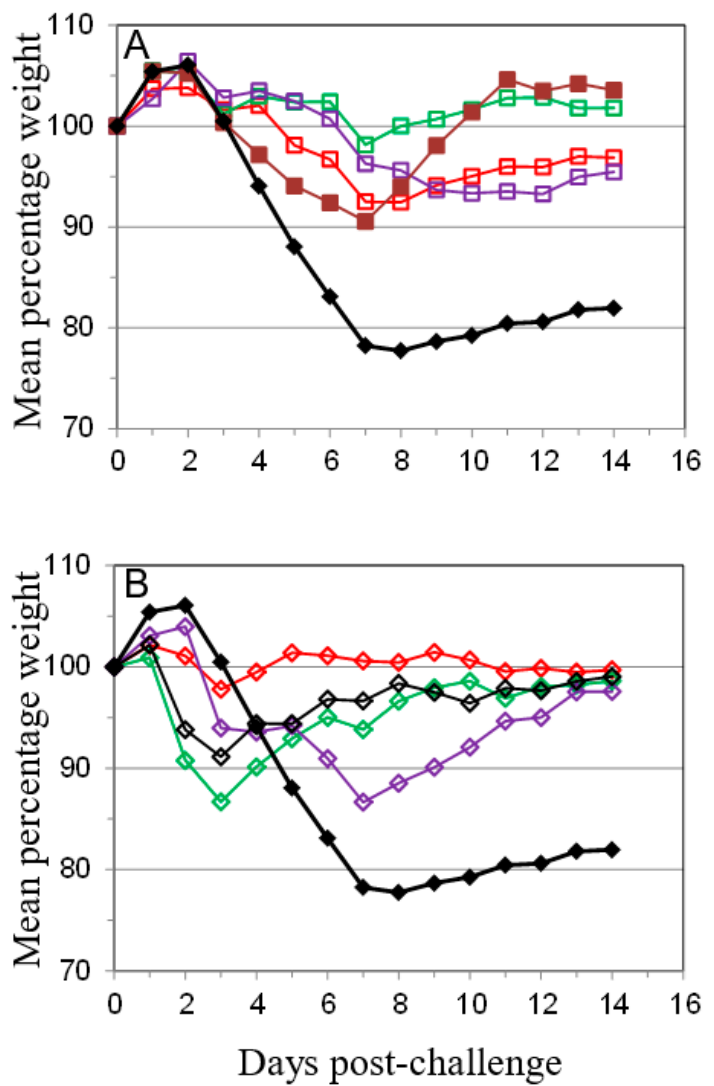

Figure 5. Effects of T cell subset depletion. Animals were vaccinated with PBS ( ), or with divalent A27/B5/CpG (A) or Lister (B) vaccines under the same dosing/challenge schedule as for Figure 1, with protein concentrations (per dose) of $10 \mu \mathrm{g}$ A27 and $10 \mu \mathrm{g}$ B5. Animals were further treated with anti-CD4 $(\square, \bullet)$; anti-CD8 $(\square, \bullet)$; anti-CD4 and anti-CD8 $(\square, \bullet)$; or non-relevant Mab $(\square, \bullet)$ as described in material methods. Weight data is presented as daily means of the weight of each surviving animal as a percentage of its initial weight. Statistical analysis was by ANOVA and 2-way ANOVA. $n=6$ animals per group. 

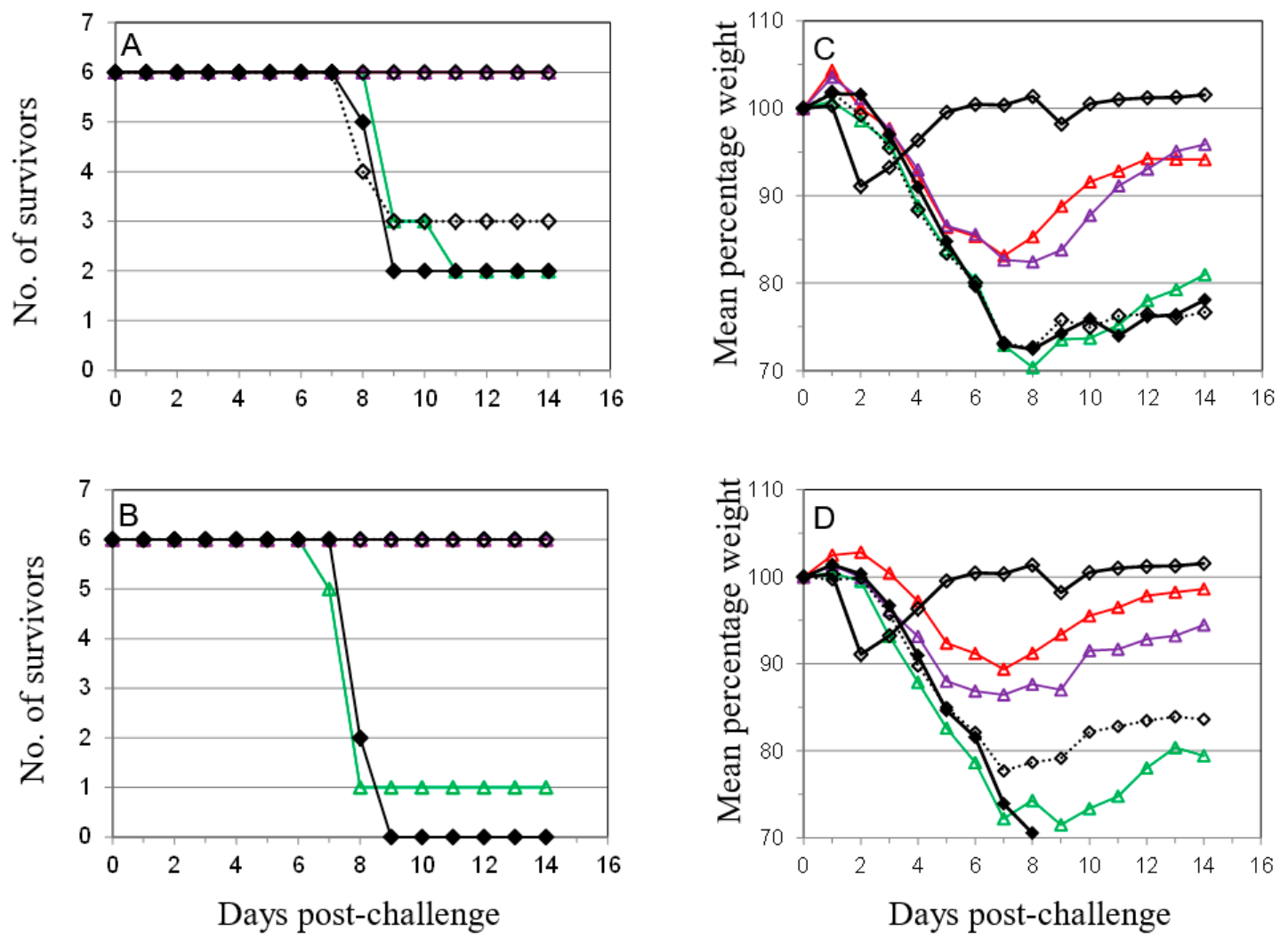

Figure 6. Protection of animals by passive transfer of Mabs. Anti-A27 $(\boldsymbol{\Delta})$, anti-B5 $(\boldsymbol{\Delta})$ or both anti-A27 and anti-B5 Mab $(\boldsymbol{\Delta})$ was administered as described in Materials and Methods in $50 \mu \mathrm{g}(\mathbf{A}, \mathbf{C})$ or $100 \mu \mathrm{g}$ (B,D) doses. Control animals were either vaccinated with Lister vaccine on the same schedule as for Figure 1 ( $)$; given purified IgG from animals vaccinated with Lister vaccine (" - - " ); or given normal rat IgG ( Mice were challenged as described above and monitored for 14 days. Data is presented as number of survivors $(\mathbf{A}, \mathbf{B})$ and daily means of the weight of each surviving animal as a percentage of its initial weight $(\mathbf{C}, \mathbf{D})$. Statistical analysis was by ANOVA and 2-way ANOVA. $n=6$ animals per group.

\section{Discussion}

Several previous studies have examined the efficacy of protein subunit vaccines for prevention of orthopoxvirus disease $[19,21-27]$. In this study, we have attempted to improve subunit vaccine approaches by formulation with a CpG adjuvant. CpG 7909 is a Toll-Like-Receptor-9 (TLR9) agonist [30,31], which we anticipated to modulate the immune response to protein antigens in a qualitative manner, relative to a more traditional adjuvant such as alhydrogel.

The combination of A27 and B5 proteins with CpG 7909 performed better than all other combinations, including the combinations that included both A27 and B5, with A33 and/or L1. This was not due to the different amounts of A27 and B5 proteins in the divalent, trivalent and quadrivalent combinations, and we surmise it may reflect competition between the various antigens for recognition by the adaptive immune system. The A27/B5/CpG7909 vaccine was equivalent to scarification with the traditional live Lister vaccine, indicating exceptionally good protection from orthopoxvirus disease in this model. Kinetic analysis of the humeral immune response demonstrated differences not only between antigens-with antibodies to A27 appearing before antibodies to other antigens-but also between adjuvants. Alhydrogel stimulated a more rapid development of A27 specific antibodies than CpG7909; however, there was no apparent difference between the adjuvants for kinetics of the response to B5. When the isotype of antibodies was examined, alhydrogel was found to bias to IgG1 antibodies for both A27 and B5, while CpG7909 was found to bias towards IgG2a. 
This is interesting from a mechanistic viewpoint, showing that the adjuvants induce qualitatively different immune responses for the same antigen. IgG2a responses are indicative of a cell-mediated response, and the data suggests that CpG7909 is facilitating the induction of cell-mediated immunity, where alhydrogel may be facilitating induction of a primarily humeral response.

It is interesting to note the results of treating animals vaccinated with A27/B5/CpG7909 or VACV Lister, with CD4+ and/or CD8+ depleting antibodies prior to challenge. On the surface it appears that depleting CD8+ cells enhanced the protective effect of A27/B5/CpG7909, while depletion of CD4+ cells enhanced the protective effect of VACV Lister. It is notable that VACV Lister recipients experience a dip in weight in the immediate post-challenge period, but this quickly recovers, and it is tempting to hypothesize that this may be an immune mediated effect of a strong, ongoing immune response that encounters a large bolus of antigen. CD4+ cells may be an essential mediator of such an effect, and their removal could thus give an apparent increase in efficacy, by negating immune-mediated illness.

In the case of A27/B5/CpG7909, there is a comparable dip in post-challenge weight, but this occurs several days later post-challenge. Thus, the post-challenge dip in weight for A27/B5/CpG7909 recipients may reflect a virus mediated disease state, rather than an immune-mediated one. However, it is difficult to see how depletion of CD8+ cells would alleviate a virus-mediated disease state. In both situations it is necessary to understand how depletion of both CD4+ and CD8+ cells does not result in reduced efficacy relative to animals treated with the non-relevant antibody.

One explanation that fits the data is that for A27/B5/CpG7909 recipients, CD8+ cells are effectors of a slow-starting, transient, immune-mediated illness, while for VACV Lister recipients CD4+ cells are effectors of a fast-starting transient immune mediated illness. In this scenario protection from disease owes much to pre-existing antibody, and thus transient depletion of both CD4+ and CD8+ $T$ cells would not result in animals succumbing to virus-mediated disease. The demonstration that passively administered anti-B5 Mab gives good protection against VACV challenge is evidence in favor of this explanation (the failure of the anti-A27 Mab to protect may be due to the particular Mab used rather than the immunogenic properties of the antigen). A proper examination of this possibility is beyond the scope of this paper, but bears future investigation. In particular, it is interesting to note that the equivalence of A27/B5/CpG7909 and the traditional Lister vaccine is determined on the basis of weight loss after challenge, but the kinetics of weight loss appear to be different for the two vaccines, and differential effects of depletion of CD4+ and CD8+ suggest that there are mechanistic differences between $\mathrm{CpG}$ adjuvant effects and the live vaccine.

In summary, we have shown that adjuvanting VACV proteins with a TLR9 agonist CpG as a subunit vaccine is able to give protection against a lethal orthopoxvirus challenge. Other researchers have examined protein subunits as potential orthopoxvirus vaccines, and have achieved protection with antigens such as A33, which was not protective in our study. However, these required a minimum of 3 doses to achieve protection, and the data are thus not inconsistent with our findings. Interestingly, these studies using non-CpG adjuvants generated primarily IgG1 antibodies, and required a minimum of 3 doses to achieve protection equivalent to vaccination with live VACV Wyeth vaccine, even when B5 was used as an antigen [22]. Thus, our data demonstrate that CpG7909 offers advantages over more traditional adjuvants, inducing an antibody response qualitatively more similar to live VACV (IgG2a/Th1), and reducing the number of doses required to generate an equivalent level of protection to live VACV. Other studies have shown the value of CpG7909 for induction of immune responses to orthopoxviruses, by combining CpG adjuvant with alum-based adjuvant. In these studies, multiple doses were also required, and antibody responses were predominantly IgG1, however this may be due to the researchers having combined CpG7909 with alum, rather than using CpG7909 by itself [23,26]. A saponin-based adjuvant, QS-21, has been shown elsewhere to reduce the number of immunizations to no more than two, and to bias to an IgG2a antibody response, in a similar manner to our findings here [25].

Our study confirms previous findings that a divalent antigen combination can offer better protection than tri- or quadrivalent vaccines. The failure of L1 to offer any protection in our study 
may be due to the reduced number of immunizations we have used. Other researchers have shown that, from antigens of the intracellular mature virus form of VACV, A27 is inferior to L1 as a subunit vaccine [22]. It is, therefore, interesting to speculate about the significance of the failure of anti-A27 Mab to protect against VACV by passive transfer, which raises the possibility that the $\mathrm{B} 5$ component of the A27/B5 combination might be solely responsible for the protection provided by A27/B5/CpG7909. However, there are other studies in which anti-A27 Mab has offered good protection by passive transfer [39], and we cannot therefore conclude that the A27 component of our divalent combination is not contributing to protection. The discrepancy between different studies with respect to efficacy of anti-A27 Mabs in passive protection may be due to differences in the Mabs, perhaps with respect to isotype, or to the specific epitope recognized.

Acknowledgments: The research was funded by the UK Ministry of Defence. The expert assistance of Dstl animal technicians is gratefully acknowledged and appreciated.

Author Contributions: Amanda J. Gates, David J. Pulford and David O. Ulaeto conceived and designed the experiments; Sarah Reeman and Amanda J. Gates performed the experiments; Amanda J. Gates, David J. Pulford and David O. Ulaeto analyzed the data; Art Krieg contributed reagents; David O. Ulaeto wrote the paper.

Conflicts of Interest: The authors declare no conflict of interest. The funding sponsors had no role in the design of the study; in the collection, analyses, or interpretation of data; or in the writing of the manuscript. Publication of the results was subject to UK Ministry of Defence clearance procedures.

\section{References}

1. Nolen, L.D.; Osadebe, L.; Katomba, J.; Likofata, J.; Mukadi, D.; Monroe, B.; Doty, J.; Hughes, C.M.; Kabamba, J.; Malekani, J.; et al. Extended human-to-human transmission during a monkeypox outbreak in the Democratic Republic of the Congo. Emerg. Infect. Dis. 2016, 22, 1014-1021. [CrossRef] [PubMed]

2. Rimoin, A.W.; Kisalu, N.; Kebela-Ilunga, B.; Mukaba, T.; Wright, L.L.; Formenty, P.; Wolfe, N.D.; Shongo, R.L.; Tshioko, F.; Okitolonda, E.; et al. Endemic human monkeypox, democratic Republic of Congo, 2001-2004. Emerg. Infect. Dis. 2007, 13, 934-937. [CrossRef] [PubMed]

3. Fuller, T.; Thomassen, H.A.; Mulembakani, P.M.; Johnston, S.C.; Lloyd-Smith, J.O.; Kisalu, N.K.; Lutete, T.K.; Blumberg, S.; Fair, J.N.; Wolfe, N.D.; et al. Using remote sensing to map the risk of human monkeypox virus in the Congo Basin. Ecohealth 2011, 8, 14-25. [CrossRef] [PubMed]

4. Brown, K.; Leggat, P.A. Human monkeypox: Current state of knowledge and implications for the future. Trop. Med. Infect. Dis. 2016, 1, 8. [CrossRef]

5. Reed, K.D.; Melski, J.W.; Graham, M.B.; Regnery, R.L.; Sotir, M.J.; Wegner, M.V.; Kazmierczak, J.J.; Stratman, E.J.; Li, Y.; Fairley, J.A.; et al. The detection of monkeypox in humans in the Western Hemisphere. N. Engl. J. Med. 2004, 350, 342-350. [CrossRef] [PubMed]

6. Fenner, F.; Henderson, D.; Arita, I.; Jezek, Z.; Ladnyi, I. Smallpox and Its Eradication; World Health Organization: Geneva, Switzerland, 1988.

7. Greenberg, R.N.; Hay, C.M.; Stapleton, J.T.; Marbury, T.C.; Wagner, E.; Kreitmeir, E.; Röesch, S.; von Krempelhuber, A.; Young, P.; Nichols, R.; et al. A Randomized, Double-Blind, Placebo-Controlled Phase II Trial Investigating the Safety and Immunogenicity of Modified Vaccinia Ankara Smallpox Vaccine (MVA-BN $^{\circledR}$ ) in 56-80-Year-Old Subjects. PLoS ONE 2016, 11, e0157335. [CrossRef] [PubMed]

8. Greenberg, R.N.; Hurley, Y.; Dinh, D.V.; Mraz, S.; Vera, J.G.; von Bredow, D.; von Krempelhuber, A.; Roesch, S.; Virgin, G.; Arndtz-Wiedemann, N.; et al. A multicenter, Open-Label, Controlled Phase II Study to Evaluate Safety and Immunogenicity of MVA Smallpox Vaccine (IMVAMUNE) in 18-40 Year Old Subjects with Diagnosed Atopic Dermatitis. PLoS ONE 2015, 10, e0138348. [CrossRef]

9. Mayr, A.; Stickl, H.; Müller, H.; Danner, K.; Singer, H. The smallpox vaccination strain MVA: Marker, genetic structure, experience gained with the parenteral vaccination and behavior in organisms with a debilitated defence mechanism (author's transl). Zentralbl. Bakteriol. B 1978, 167, 375-390. [PubMed]

10. Yokote, H.; Shinmura, Y. Reply to "Use of the LC16m8 Smallpox Vaccine in Immunocompromised Individuals Is Still Too Risky". Clin. Vaccine Immunol. 2015, 22, 605. [CrossRef] [PubMed] 
11. Yokote, H.; Shinmura, Y.; Kanehara, T.; Maruno, S.; Kuranaga, M.; Matsui, H.; Hashizume, S. Safety of attenuated smallpox vaccine LC16m8 in immunodeficient mice. Clin. Vaccine Immunol. 2014, 21, 1261-1266. [CrossRef] [PubMed]

12. Yamaguchi, M.; Kimura, M.; Hirayama, M. Report of the National Smallpox Vaccination Research Committee: Study of side effects, complications and their treatments. Clin. Virol. 1975, 3, 269-278.

13. Danon, Y.L.; Sutter, G. Use of the LC16m8 smallpox vaccine in immunocompromised individuals is still too risky. Clin. Vaccine Immunol. 2015, 22, 604. [CrossRef] [PubMed]

14. Eto, A.; Saito, T.; Yokote, H.; Kurane, I.; Kanatani, Y. Recent advances in the study of live attenuated cell-cultured smallpox vaccine LC16m8. Vaccine 2015, 33, 6106-6111. [CrossRef] [PubMed]

15. Hooper, J.; Custer, D.; Thompson, E. Four-gene-combination DNA vaccine protects mice against a lethal vaccinia virus challenge and elicits appropriate antibody responses in nonhuman primates. Virology 2003, 306, 181-195. [CrossRef]

16. Hooper, J.; Thompson, E.; Wilhelmsen, C.; Zimmerman, M.; Ichou, M.A.; Steffen, S.; Schmaljohn, C.; Schmaljohn, A.; Jahrling, P. Smallpox DNA vaccine protects nonhuman primates against lethal monkeypox. J. Virol. 2004, 78, 4433-4443. [CrossRef] [PubMed]

17. Pulford, D.; Gates, A.; Bridge, S.; Robinson, J.; Ulaeto, D. Differential efficacy of vaccinia virus envelope proteins administered by DNA immunisation in protection of BALB/c mice from a lethal intranasal poxvirus challenge. Vaccine 2004, 22, 3358-3366. [CrossRef] [PubMed]

18. Moss, B. Smallpox vaccines: Targets of protective immunity. Immunol. Rev. 2011, 239, 8-26. [PubMed]

19. Sakhatskyy, P.; Wang, S.; Te-hui, W.C.; Lu, S. Immunogenicity and protection efficacy of monovalent and polyvalent poxvirus vaccines that include the D8 antigen. Virology 2006, 355, 164-174. [CrossRef] [PubMed]

20. Galmiche, M.C.; Goenaga, J.; Wittek, R.; Rindisbacher, L. Neutralizing and protective antibodies directed against vaccinia virus envelope antigens. Virology 1999, 254, 71-80. [CrossRef] [PubMed]

21. Davies, D.H.; McCausland, M.M.; Valdez, C.; Huynh, D.; Hernandez, J.E.; Mu, Y.; Hirst, S.; Villarreal, L.; Felgner, P.L.; Crotty, S. Vaccinia virus H3L envelope protein is a major target of neutralizing antibodies in humans and elicits protection against lethal challenge in mice. J. Virol. 2005, 79, 11724-11733. [CrossRef] [PubMed]

22. Fogg, C.; Lustig, S.; Whitbeck, J.C.; Eisenberg, R.J.; Cohen, G.H.; Moss, B. Protective immunity to vaccinia virus induced by vaccination with multiple recombinant outer membrane proteins of intracellular and extracellular virions. J. Virol. 2004, 78, 10230-10237. [CrossRef] [PubMed]

23. Fogg, C.N.; Americo, J.L.; Lustig, S.; Huggins, J.W.; Smith, S.K.; Damon, I.; Resch, W.; Earl, P.L.; Klinman, D.M.; Moss, B. Adjuvant-enhanced antibody responses to recombinant proteins correlates with protection of mice and monkeys to orthopoxvirus challenges. Vaccine 2007, 25, 2787-2799. [CrossRef] [PubMed]

24. Lai, C.; Gong, S.; Esteban, M. The purified 14-kilodalton envelope protein of vaccinia virus produced in Escherichia coli induces virus immunity in animals. J. Virol. 1991, 65, 5631-5635. [PubMed]

25. Berhanu, A.; Wilson, R.L.; Kirkwood-Watts, D.L.; King, D.S.; Warren, T.K.; Lund, S.A.; Brown, L.L.; Krupkin, A.K.; VanderMay, E.; Weimers, W. Vaccination of BALB/c mice with Escherichia coli-expressed vaccinia virus proteins A27L, B5R, and D8L protects mice from lethal vaccinia virus challenge. J. Virol. 2008, 82, 3517-3529. [CrossRef] [PubMed]

26. Buchman, G.W.; Cohen, M.E.; Xiao, Y.; Richardson-Harman, N.; Silvera, P.; DeTolla, L.J.; Davis, H.L.; Eisenberg, R.J.; Cohen, G.H.; Isaacs, S.N. A protein-based smallpox vaccine protects non-human primates from a lethal monkeypox virus challenge. Vaccine 2010, 28, 6627-6636. [CrossRef]

27. Heraud, J.-M.; Edghill-Smith, Y.; Ayala, V.; Kalisz, I.; Parrino, J.; Kalyanaraman, V.S.; Manischewitz, J.; King, L.R.; Hryniewicz, A.; Trindade, C.J.; et al. Subunit recombinant vaccine protects against monkeypox. J. Immunol. 2006, 177, 2552-2564. [CrossRef] [PubMed]

28. Bretscher, P. On the mechanism determining the TH1/TH2 phenotype of an immune response, and its pertinence to strategies for the prevention, and treatment, of certain infectious diseases. Scand. J. Immunol. 2014, 79, 361-376. [CrossRef] [PubMed]

29. Ramírez, J.C.; Gherardi, M.M.; Esteban, M. Biology of attenuated modified vaccinia virus Ankara recombinant vector in mice: Virus fate and activation of B-and T-cell immune responses in comparison with the Western Reserve strain and advantages as a vaccine. J. Virol. 2000, 74, 923-933. [CrossRef] [PubMed] 
30. Chu, R.S.; Targoni, O.S.; Krieg, A.M.; Lehmann, P.V.; Harding, C.V. CpG oligodeoxynucleotides act as adjuvants that switch on T helper 1 (Th1) immunity. J. Exp. Med. 1997, 186, 1623-1631. [CrossRef] [PubMed]

31. Krieg, A.M.; Davis, H.L. CpG ODN as a Th1 immune enhancer for prophylactic and therapeutic vaccines. In Vaccine Adjuvants; Humana Press Inc.: Totowa, NJ, USA, 2006; pp. 87-110.

32. Davis, H.L.; Weeranta, R.; Waldschmidt, T.J.; Tygrett, L.; Schorr, J.; Krieg, A.M. CpG DNA is a potent enhancer of specific immunity in mice immunized with recombinant hepatitis B surface antigen. J. Immunol. 1998, 160, 870-876. [PubMed]

33. Cooper, C.; Davis, H.; Morris, M.; Efler, S.; Al Adhami, M.; Krieg, A.; Cameron, D.; Heathcote, J. CpG 7909, an immunostimulatory TLR9 agonist oligodeoxynucleotide, as adjuvant to Engerix- $\mathrm{B}^{\circledR} \mathrm{HBV}$ vaccine in healthy adults: A double-blind phase I/II study. J. Clin. Immunol. 2004, 24, 693-701. [CrossRef] [PubMed]

34. Cooper, C.; Davis, H.; Morris, M.; Efler, S.; Krieg, A.; Li, Y.; Laframboise, C.; Al Adhami, M.; Khaliq, Y.; Seguin, I.; et al. Safety and immunogenicity of CpG 7909 injection as an adjuvant to Fluarix influenza vaccine. Vaccine 2004, 22, 3136-3143. [CrossRef] [PubMed]

35. Krieg, A.M. CpG still rocks! Update on an accidental drug. Nucleic Acid Ther. 2012, 22, 77-89. [PubMed]

36. Krieg, A.M. CpG motifs: The active ingredient in bacterial extracts? Nat. Med. 2003, 9, 831-835. [CrossRef] [PubMed]

37. Phelps, A.; Gates, A.; Hillier, M.; Eastaugh, L.; Ulaeto, D. Comparative efficacy of replicating smallpox vaccine strains in a murine challenge model. Vaccine 2005, 23, 3500-3507. [CrossRef] [PubMed]

38. Ramírez, J.C.; Tapia, E.; Esteban, M. Administration to mice of a monoclonal antibody that neutralizes the intracellular mature virus form of vaccinia virus limits virus replication efficiently under prophylactic and therapeutic conditions. J. Gen. Virol. 2002, 83, 1059-1067. [CrossRef] [PubMed]

39. Phelps, A.; Gates, A.; Eastaugh, L.; Hillier, M.; Ulaeto, D. Comparative efficacy of intramuscular and scarification routes of administration of live smallpox vaccine in a murine challenge model. Vaccine 2017, 35, 3889-3896. [CrossRef] [PubMed]

(C) Crown copyright (2017), Dstl. This material is licensed under the terms of the Open Government Licence except where otherwise stated. To view this licence, visit http://www.nationalarchives.gov.uk/doc/opengovernment-licence/version/3 or write to the Information Policy Team, The National Archives, Kew, London TW9 4DU, or email: psi@nationalarchives.gsi.gov.uk. 